\title{
Essais
}

ESSAIS

Revue interdisciplinaire d'Humanités

Résister entre les lignes

\section{El potencial político del gesto: Una introducción a ZAJ a través de sus propuestas}

\section{Diego Luna Delgado}

\section{OpenEdition}

1 Journals

\section{Edición electrónica}

URL: http://journals.openedition.org/essais/4387

DOI: $10.4000 /$ essais.4387

ISSN: 2276-0970

\section{Editor}

École doctorale Montaigne Humanités

\section{Edición impresa}

Fecha de publicación: 15 julio 2016

Paginación: 48-63

ISBN: 978-2-9544269-8-3

ISSN: $2417-4211$

\section{Referencia electrónica}

Diego Luna Delgado, «El potencial político del gesto: Una introducción a ZAJ a través de sus propuestas », Essais [En ligne], 9 | 2016, mis en ligne le 23 octobre 2020, consulté le 31 octobre 2020. URL : http://journals.openedition.org/essais/4387 ; DOI : https://doi.org/10.4000/essais.4387 


\title{
El potencial político del gesto: Una introducción a ZAJ a través de sus propuestas ${ }^{1}$
}

\author{
Diego Luna Delgado
}

\section{¿Qué es ZAJ?}

Son muchos los motivos que nos permiten entender hoy el trabajo artístico de ZAJ, grupo español activo entre 1964 y 1996, como un referente claro dentro de la historia de la resistencia política en la Espańa contemporánea. En un panorama artístico donde, como bien ha sintetizado Juan Albarrán, "se atesoraba una serie de valores universales que emanaban de una individualidad genial y que se condensaban en obras eminentemente realistas cuya promoción y difusión (léase instrumentalización) eran responsabilidad del Estado"2, las dificultades para las propuestas más arriesgadas no debieron ser pocas ${ }^{3}$.

1 Este trabajo constituye una versión revisada de nuestra comunicación presentada en la $5^{\mathrm{e}}$ Journée des doctorants, Penser et dire les résistances, celebrada en la Université Bordeaux Montaigne los días 5 y 6 de junio de 2014. Asimismo, para profundizar en el recorrido que aquí se plantea recomendamos ver nuestro trabajo monográfico: Diego Luna, ZAJ: Arte y política en la estética de lo cotidiano, Juan Bosco Díaz-Urmeneta (introd.), Sevilla, Athenaica, 2015.

2 Juan Albarrán, "Del desarrollismo al entusiasmo: Notas sobre el arte español en tiempos de transición", en Foro de Educación, n¹0, 2008, p. 170.

3 Para un conocimiento general de los fenómenos marginales o represaliados dentro de la situación cultural durante el período franquista, marco en el que aquí nos moveremos, hemos de destacar las siguientes obras: Elías Díaz, Ética contra política: los intelectuales y el poder, Madrid, Centro de Estudios Constitucionales, 1990, y Los viejos maestros: la reconstrucción de la razón, Madrid, Alianza, 1994; Shirley Mangini, Rojos y rebeldes: la cultura de la disidencia durante el franquismo, Barcelona, Anthropos, 1987; Jordi Gracia, La resistencia silenciosa: fascismo y cultura en España, Barcelona, Anagrama, 2004, y Estado y cultura: el despertar de una conciencia critica bajo el franquismo, 1940-1962, Barcelona, Anagrama, 2006. A partir de aquí, centrándonos en las prácticas artísticas: Miguel Cabañas Brazo, La política artística del Franquismo: el hito de la Bienal Hispanoamericana de arte, Madrid, CSIC, 1996; Jorge Luis Marzo, ¿Puedo hablarle con libertad, excelencia?: Arte y poder en Espańa desde 1950, Murcia, CENDEAC, 2010; Mónica Núñez Laiseca, Arte y politica en la España del Desarrollismo (1962-1968), Madrid, Consejo Superior de Investigaciones Científicas, 2006; Pilar Parcerisas, Conceptualismo(s) poéticos, politicos y periféricos: En torno al arte conceptual en España, 1964-1980, Madrid, Akal, 2007. 
Testigo y víctima directa de la represión franquista, ZAJ constituye todo un ejemplo de la capacidad de canalizar un malestar colectivo mediante un tipo de expresión creativa completamente liberada de toda suerte de coerciones. Apoyada en diversos elementos presentes en la contracultura internacional de los años sesenta del pasado siglo, las propuestas de ZAJ, como aquí mostraremos, pueden ser ahora leídas, cincuenta años más tarde de su aparición, como estímulos válidos para seguir concibiendo en los planos artístico y político nuevas formas de resistencia ante las nuevas formas de control social. Más allá de los marcos históricos o epistemológicos, la práctica zajiana, después de todo, destacaba básicamente por su capacidad para subvertir ciertos paradigmas culturales utilizando los medios y canales más sencillos, aquellos que estaban a disposición de cualquier individuo, en la propia realidad cotidiana. En este sentido, un acercamiento descriptivo a la producción global del grupo, desde una lectura de su poética marginal entendida como forma de resistencia política en su particular contexto, será nuestro propósito en este trabajo.

Respecto a la pregunta “¿Qué es ZAJ?”, debemos decir que no existe una única respuesta. Según decía Walter Marchetti en uno de los cartones más emblemáticos del grupo: "ZAJ es como un bar. La gente entra, sale, está; se toma una copa y deja una propina" $(1966)^{4}$. Una definición que, de entrada, invita a pensar ZAJ como una suerte de renovado Cabaret Voltaire dadaísta, y que sería completada o rebatida irónicamente por Ramón Barce, otro de los integrantes fundadores, quien llegó a asegurar que fue él mismo quien bautizó al grupo uniendo "tres sonidos característicos del español que en muchos idiomas no están o no están de la manera que están en español: la "z", que en muchos idiomas no la tienen; la " $j$ ", que en muchos idiomas tampoco la tienen y la "a", que es la vocal más abundante en el español"; una sencilla explicación que por alguna razón tampoco termina de convencernos. Una tercera visión del grupo vendría de la mano del último componente fundador, el canario Juan Hidalgo, quien, formado en estudios sobre culturas orientales en Milán y Roma, fue el principal promotor en ZAJ de esa particular dimensión práctica y espiritual propia del Budismo Zen. Por medio de un célebre fotomontaje titulado Zajografía (1975), que podemos analizar en paralelo a una cita muy conocida de Hidalgo, el autor mostraba una sucinta genealogía siguiendo sus principales influencias recibidas: "Mi padre es John Cage, aunque me llame Hidalgo; Marcel Duchamp, mi abuelo, aunque no se llame Cage; el amigo de

4 El cartón se encuentra reproducido en: José Antonio Sarmiento (ed.) et al., ZAJ [Catálogo de la exposición]: Museo Nacional Centro de Arte Reina Sofía, 23 de enero - 21 de marzo, 1996, Madrid, Museo Nacional Centro de Arte Reina Sofía, 1996, p. 93.

5 José Iges y Ricardo Bellés, ZAJ: 40 años, Radio Clásica, 2004; citado por José Antonio Sarmiento (ed.), ZAJ: Concierto de teatro musical, Córdoba, Senxperiment, 2007, p. 7. Disponible en: <http://www.sensxperiment.es/publicaciones-zaj/> [Último acceso el 10/05/2015]. 
la familia, Erik Satie; y el amigo de los amigos, Buenaventura Durruti... en cuanto a mis bisabuelos, chinos pudieron ser" $[\text { sic }]^{6}$. Una serie de personajes que guardan en común el hecho de ser declarados anarquistas, y de entre los que debemos destacar la figura de John Cage, sin duda alguna el compositor de vanguardia más importante del siglo $\mathrm{XX}$, discípulo aventajado de Duchamp y deudor asimismo del componente azaroso de la filosofía Zen ${ }^{7}$.

Del Zen surgirían precisamente las dos afirmaciones que quizás sinteticen mejor la esencia de la identidad y la filosofía creativa de ZAJ: “¿qué es ZAJ? ZAJ es ZAJ porque ZAJ es no-ZAJ?”, del propio Juan Hidalgo, y "ZAJ es una posibilidad llevada a la práctica", de Esther Ferrer', quien se incorporaría al grupo en el año 1967. Dos definiciones que reflejan definitivamente la singular poética zajiana: un modo de hacer, estético a la vez que político, cuyos vectores de acción se situarían en un espacio sin nombre, en los propios márgenes de lo común, esto es, en un posicionamiento limítrofe y crítico en el sentido foucaultiano ${ }^{10}$. Desde esta perspectiva debemos pensar ZAJ como un fenómeno artístico que se enmarca históricamente en el escenario de unas prácticas radicalmente rupturistas, las cuales, desde su propia razón de ser, atentan sin reparo contra cualquier patrón preestablecido: contra la Academia, contra el sistema del arte y contra el propio concepto de "arte". Unas prácticas situadas cronológicamente dentro de una etapa de experimentación artística internacional, acontecida tras la Segunda Guerra Mundial, y en concreto en un punto muy especial de conexión entre el desarrollo de la música de vanguardia, por un lado, y, por otro, la profusión de las derivas conceptualistas aparecidas en las artes visuales en paralelo al comúnmente denominado

6 Juan Hidalgo et al., Juan Hidalgo en medio del volcán, Madrid, Dirección General de Relaciones Culturales y Científicas del Ministerio de Asuntos Exteriores y Sociedad Estatal para la Acción Cultural Exterior, 2004, p. 1.

7 En cierto modo, podríamos afirmar que la importancia de Cage en la evolución hacia la performatividad de la música de acción reside básicamente en la recepción o adaptación, consciente o inconsciente, de los valores duchampianos al ámbito musical, concretamente en la asimilación y ampliación del concepto de readymade. No obstante, en Duchamp se encuentran ya, curiosamente, algunos de los intentos más radicales por subvertir los límites musicales. Experimentos o juegos como el de Erratum Musical (1913), composición elaborada junto con sus hermanas a partir de la selección azarosa de una serie de trozos de cartón con notas apuntadas, nos permiten rastrear el origen moderno de la composición musical aleatoria. Cf. Javier Ariza, Las imágenes del sonido: Una lectura plurisensorial del arte del siglo XX, Cuenca, Ediciones de la Universidad de Castilla-La Mancha, 2008 (1ª ed. 2003), p. 33-40.

8 Juan Hidalgo, Juan Hidalgo de Juan Hidalgo (1961-1991), Valencia, Pre-textos, 1991, s. p.

9 Esther Ferrer, Entrevista con el autor, París, 2014.

10 En sus orígenes, como bien ha sintetizado Juan Pablo Wert, "la práctica accionista compartió con el arte de los procesos (processual art), el del cuerpo (body art) y el de la tierra (land art, earthworks) un marco estratégico común en el que el objetivo de la actividad artística no se orientaba ya a la producción de objetos sino a la transformación del entorno físico y social”, Juan Pablo Wert, "Sobre el arte de acción en España", en Artes de la escena y de la acción en España: 1978-2002, J.A. Sánchez (ed.), Cuenca: Universidad de Castilla-La Mancha, p. 36. 
"arte conceptual", movimiento cuyo punto álgido se situaría en las propuestas del conceptual lingüístico de Joseph Kosuth y el grupo Art and Language ${ }^{11}$.

Tras una etapa pre-ZAJ en la que Hidalgo y Marchetti estuvieron formándose en Europa al lado de compositores de vanguardia de reconocido prestigio, y en torno a los famosos "cursos de Darmstadt", ZAJ fue creado de manera oficial en Madrid en 1964. Un primer cartón a modo de presentación hacía las veces de partida de nacimiento de la criatura: se trataba de una invitación a un evento acontecido dos días antes; una curiosa forma de empezar a caminar, nunca mejor dicho, pues el evento consistió sorprendentemente en "el traslado a pie de tres objetos de forma compleja" 12 . En dicha nota, firmada por los tres miembros cofundadores - Hidalgo, Marchetti y Barce- y difundida por correo postal, se anunciaba -o recordaba- en qué había consistido tal suceso con todo lujo de detalles. El hecho de plantear una obra artística consistente en el traslado de tres piezas de madera y simbolizarlo por medio de un documento de difusión carente de toda pretensión artística nos habla ya de entrada de un desvío radical de la importancia de lo material hacia la idea. Una primera acción zajiana cuya naturaleza nómada no distaría mucho de las derivas situacionistas llevadas a cabo escasos años más tarde por Guy Debord y compañía a partir del Mayo del 68 francés, y que acreditaría a ZAJ como el legítimo iniciador del arte de acción en España $^{13}$. Un privilegio que, no obstante, debido a la ausencia de un contexto cultural acorde con la sensibilidad del momento, obligaría al grupo a mantenerse siempre totalmente al margen del circuito oficial del arte; circunstancia que le llevó a realizar actuaciones en lugares tan dispares como colegios mayores, calles, plazas, facultades, trenes, etc ${ }^{14}$. Las prácticas zajianas no eran precisamente plato

11 Para un visión panorámica de los comportamientos artísticos de la segunda mitad del siglo XX destacamos las siguientes obras: Simón Marchán Fiz, Del arte objetual al arte de concepto, Madrid, Akal, 1994 ( $1^{\text {a }}$ ed. 1972); y Anna Maria Guasch, El arte último del siglo XX: Del posminimalismo a lo multicultural, Madrid, Alianza Editorial, 2000. Asimismo, de cara a una lectura alternativa del arte del siglo XX centrada en una hibridación interdisciplinar en torno a la música -cuyos orígenes se remontan a las Vanguardias Históricas-, la obra de referencia es la de Javier Ariza, Las imágenes del sonido: Una lectura plurisensorial del arte del siglo XX, op. cit.

12 El cartón se encuentra reproducido en: José Antonio Sarmiento (ed.) et al., ZAJ [Catálogo de la exposición]: Museo Nacional Centro de Arte Reina Sofia, 23 de enero - 21 de marzo, 1996, op. cit., p. 63.

13 El "arte de acción" constituye el último paso del proceso de desmaterialización de la obra de arte -usando el recurrente término que Lucy R. Lippard pusiera en circulación (Seis años: la desmaterialización del objeto artístico de 1966 a1972, M.L. Rodríguez (trad.), Madrid, Akal, 2004)-, en tanto que, al concebir la obra como una acción cualquiera, esto es, un movimiento real con una determinada intención (incluso con una intención de no tener intención alguna, como a menudo ocurriese en ZAJ), existe la posibilidad de no precisar más que del propio cuerpo del artista, de su mera presencia.

14 Según David Pérez, el nomadismo marginal de ZAJ vendría a ser "heredero de lo que podríamos denominar esa tradición del exilio que en tantas ocasiones ha configurado la cultura española, (y que) convertirá el cambio en una actitud, la transitoriedad en un estado y el devenir en una certeza en perpetua transformación”, David Pérez, El margen inconcluso: Juan Hidalgo y la 
de buen gusto para las instituciones franquistas, ni mucho menos para coleccionistas de paladares, por lo general, poco educados en los nuevos derroteros que en aquellos tiempos andaba surcando la experimentación artística ${ }^{15}$. Sin embargo, según aseguraba Esther Ferrer: "Estábamos muy contentos de no existir para esta gente (...)"16. Un motivo por el que, pese a que su atractivo en otros países fuera en aumento con el paso de los años, el rechazo y el encubrimiento de ZAJ, incluso por parte del propio ámbito artístico-musical, sería la nota predominante en España hasta prácticamente su disolución en 1996, coincidiendo, paradójicamente, con la única exposición antológica del grupo realizada hasta la fecha ${ }^{17}$.

\section{Propuestas y actividades ZAJ}

¿qué cosas hace ZAJ?

-traslados, conciertos, escritos y cartones, festivales, exposiciones, libros, tarjetas, etcétera y etcéteras $\mathrm{ZAJ}^{18}$.

Adentrándonos en las "cosas" que hizo ZAJ, debemos señalar en primer lugar la gran variedad de expresiones que el grupo trabajase. Destaca, ante todo, la existencia de un conjunto heterogéneo de medios, todos ellos marcados por una característica actitud irreverente, ácrata y libre, que girarían siempre en torno a una idea de musicalidad expandida cuyo ejemplo más significativo sería la denominada "música de acción", práctica intermedial de la que el grupo fue su principal representante en España ${ }^{19}$. Con el fin de aproxi-

promiscuidad ZAJ [tesis doctoral], Valencia, Universidad Politécnica de Valencia (Sin publicar), 1992, p. 74.

15 Como muestra de ello cabe recordar el hecho de que algunos de los considerados grandes constructores de la Historia del Arte español más reciente optasen en sus obras "fundacionales" por pasar por alto el trabajo desempeńado por ZAJ o que, en el mejor de los casos, redujeran su mención a una tímida nota a pie de página. Hablamos de autores y obras como: Valeriano Bozal, Historia del Arte en España, Madrid, Istmo, 1972; Simón Marchán Fiz, Del arte objetual al arte de concepto, Madrid, Alberto Corazón Editor, 1974; Tomás Llorens I Valeriano Bozal, España. Vanguardia artística y realidad social: 1936-1976, Barcelona, Gustavo Gili, 1976; o Francisco Calvo Serraller et al., España. Medio siglo de arte de vanguardia, 1939-1985, Fundación Santillana/Ministerio de Cultura, 1985.

16 Esther Ferrer, Entrevista con el autor, op. cit.

17 José Antonio Sarmiento (ed.) et al., ZAJ [Catálogo de la exposición]: Museo Nacional Centro de Arte Reina Sofía, 23 de enero - 21 de marzo, 1996, op. cit.

18 Citado por ibid., p. 69.

19 En palabras de Juan Hidalgo: "Lo que Walter Marchetti y yo estamos haciendo desde el 58 o 59 es música de acción. Piezas, composiciones, donde, por ejemplo, mezclamos un piano con objetos no sonoros y con acciones. En un proceso musical tú puedes hacer que todos los objetos sean sonoros, tal y como ocurre en una pieza de música tradicional, e incluso en una pieza contemporánea. O puedes cambiar ciertos objetos sonoros por objetos de otro tipo que pueden ser visuales, colorísticos, movimientos. Ese es el primer paso. Luego llega el momento en el que puedes abolir lo que es instrumental y realizar un proceso temporal y espacial con objetos no sonoros exclusivamente. Estos objetos no sonoros van sin embargo a producir 
marnos a la naturaleza de la peculiar forma de resistencia política escondida tanto en este lenguaje como en el resto de campos en los que ZAJ se desenvolviera, procederemos al desarrollo de un recorrido panorámico a través de algunas obras especialmente representativas, siguiendo la estela de la desmaterialización progresiva de la obra de arte en ZAJ, es decir, la pérdida de las cualidades físicas del producto artístico, característica por otra parte de toda práctica conceptualista. En este sentido, comenzaremos nuestro trayecto en el terreno musical, del que ZAJ nace, como ya hemos apuntado, comprobando la importancia otorgada al piano como algo más que un instrumento sonoro. A partir de aquí continuaremos observando el uso por parte del grupo de todo tipo de objetos - musicales o no-, y la derivación de estos planteamientos en la ausencia de dichos objetos y a favor del protagonismo absoluto de la poesía pura, sin ningún tipo de coerción gramatical, en diferentes soportes lingüísticos ${ }^{20}$. Finalmente, concluiremos nuestro camino con la poeticidad mínima que en ZAJ llegaría a darse: la mera expresión gestual del cuerpo.

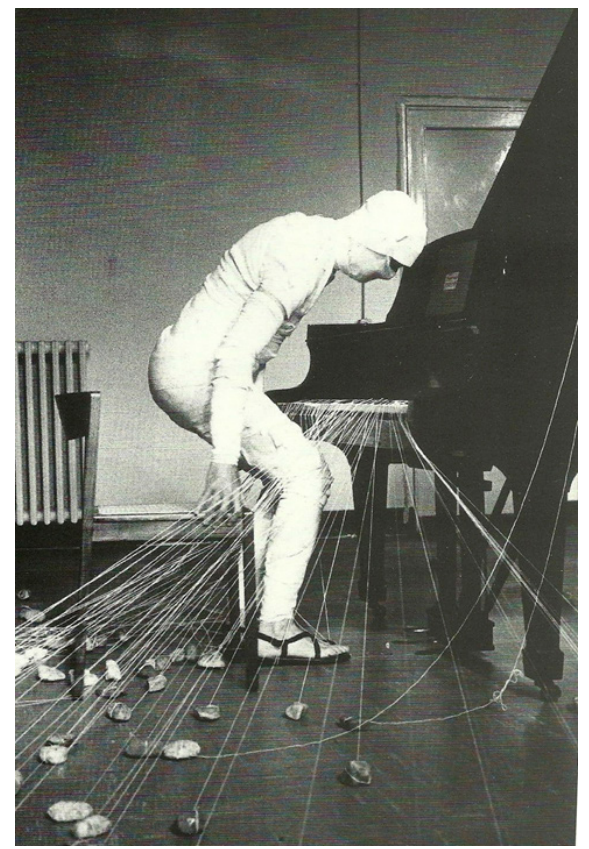

Figura 1: Walter Marchetti, J'aimerais jouer avec un piano qui aurait une grosse queue (Milán, 1975).

siempre un sonido, porque te vas a encontrar con la respuesta de un público que va a estar emitiendo una cantidad de sonidos a los que hay que ańadir todos los sonidos ambientales", citado por Carlos Jiménez, “ZAJ: El oído en el ojo”, en Lápiz, n56, febrero, 1989, p. 43.

20 Valdría tener en cuenta la definición del tipo de "poesía de acción” que propuso Juan Hidalgo en el siguiente etcétera: “¿POESÍA DE ACCIÓN? / VER / OÍR / OLER / GUSTAR / TOCAR”, citado por David Pérez, El margen inconcluso: Juan Hidalgo y la promiscuidad ZAJ [tesis doctoral], op. cit., p. 683. 
El piano, en primer lugar, es utilizado en ZAJ desde sus mismos orígenes como "piano preparado", la aportación más influyente de John Cage -recordemos, el "padre ZAJ" - en lo que a innovación técnica se refiere. Partiendo del interés de este último por el ruido y el azar, dicho invento consistía en un piano convencional al que meticulosamente se le habían ańadido una serie de elementos adicionales, perfectamente recogidos en la partitura correspondiente: tornillos y tuercas, trozos de goma, fieltros, frutos secos, canicas... Se trataba de una técnica que permitía modificar el sonido original de la cuerda ampliando sus posibilidades musicales hasta el infinito. Sin embargo, la radical experimentación que ZAJ llevaría a cabo le animaría a investigar, a partir de la manipulación del instrumento, incluso las cualidades extramusicales del piano: un intento por encontrar una supuesta musicalidad -ya sin sonidos- en cualquier tipo de intervención sobre este ${ }^{21}$. El piano, por ello mismo, comenzaría rápidamente a ser comprendido en ZAJ casi como un atrezo, como una herramienta más de una acción que se opone progresivamente a lo teatral, cuyo fin no es otro que el de superar las limitaciones musicales del concierto clásico para interpretar realidades que escapan a todo intento de ser explicadas o representadas. Se inauguraba de este modo la fuerza del gesto real, no representativo, que invitaba al espectador a cuestionar sus propios modos de actuar, primero en el propio concierto como "hecho social" subvertido, y tras ello, en su vida cotidiana. Llegados a este punto, como plantease Walter Marchettipor medio de sus múltiples pianos intervenidos, el piano como instrumento podría ser completamente transgredido, perdiendo su función original y comenzando a presentarse como un objeto que testimonia la acción real que a partir de él se ha llevado a cabo o puede llevarse. Un hecho que implicaba la adopción de un fuerte potencial evocador o alegórico, similar al del ready-made duchampiano, y analizable solo en términos de una "iconología de las connotaciones" del tipo que defendiese Juan Antonio Ramírez ${ }^{22}$. Una carga poética que llegaba incluso a soportar la propia ausencia del piano tal y como ocurriese en la pieza Música para un piano vacante (1966) de Juan Hidalgo y José Luis Castillejo, obra que nos llevaría al siguiente tramo de nuestro recorrido: el recurso por parte de ZAJ de objetos de todo tipo.

21 En palabras de Tomás Marco: "A primera vista podría parecer que el hecho de cerrar la tapa de un piano o de trasladar su banqueta nada tiene que ver en sí con el de dar un concierto, pese a ser actividades que todo concertista desarrolla siempre. No obstante, la música de acción se basa en esa serie de acciones musicales que acompañan al sonido [...].Según ello, los límites de la música de acción con los del teatro musical son muy confusos. En este tipo de teatro musical, las acciones y objetos, es decir, la parte visual, tienen tanta importancia o más que la auditiva, que, en ocasiones, se reduce al mínimo o, incluso, no existe. Para algunos, esto ya no es música; en realidad, tampoco tendría mayor importancia. Lo que sí es seguro es que tampoco es pintura, literatura ni teatro, ya que se huye de cualquier tipo de puesta en escena, y el espectáculo desarrollado es de naturaleza abstracta y estructura musical", Tomás Marco, “Zaj”, en Teleradio, n426, 21-27 de febrero, 1966, p. 36-37.

22 Juan Antonio Ramírez, "Iconografía e iconología", in Valeriano Bozal (ed.), Historia de las ideas estéticas y de las teorias artísticas contemporáneas, vol. II, Madrid, Antonio Machado Libros, 2002, p. 293-310. 


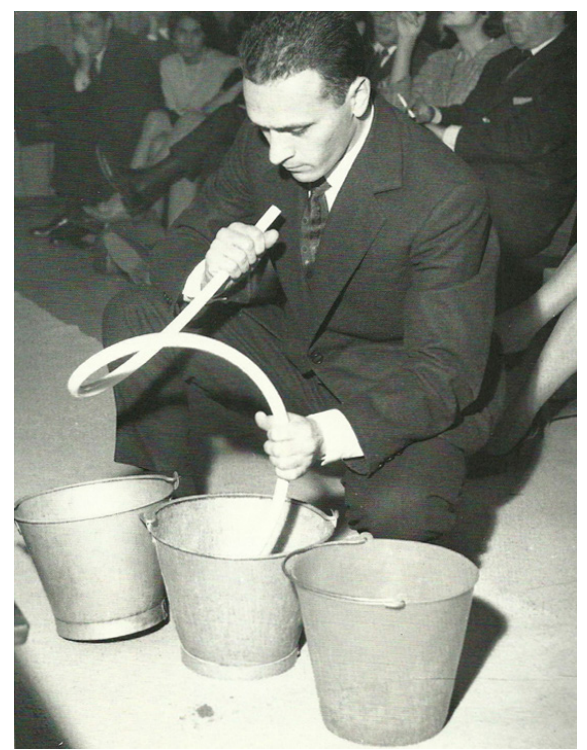

Figura 2: Walter Marchetti interpretando Variations $I V$, de John Cage, en el Primer Concierto ZAJ (Madrid, 1964).

Objetos que, al igual que el piano, comenzarían a utilizarse ligados siempre a sus cualidades sonoras. Así había venido ocurriendo ya en el trabajo del propio John Cage en obras como Variations IV (1963), pieza "burbujeante" que sería interpretada por Walter Marchetti en el primer Concierto ZAJ soplando por una manguera introducida en cubos con agua. Del mismo modo, cabe destacar la variedad de objetos utilizados por Tomás Marco, eminente musicólogo y compositor español que también pasó por ZAJ, en obras como El pájaro de fuego (1965) o Wedding (1966). Algunos de estos objetos eran utilizados con el fin de producir algún tipo de sonido, mientras otros tantos empezaban a ser tomados simplemente como instrumentos poéticos en la medida en que mostraban una esencialidad humana última, una sensibilidad incapaz de distinguir entre olores, sonidos o colores. Así lo vemos por ejemplo en la acción Arpocratesedutosul loto (1965) de Marchetti, en la que el autor se limitaba a lavarse los pies, dirigiendo sobre su propio cuerpo la función de los instrumentos elegidos. En cualquier caso, al igual que ocurría con el piano, también se llegaron a constituir como obras artísticas algunos objetos cualesquiera que, tras la mínima intervención de ZAJ, se convertían en contenedores de los más diversos significados por parte del espectador. Una idea que sin duda le debía mucho a la célebre rueda de bicicleta sobre taburete o al urinario de Marcel Duchamp -el abuelo ZAJ-, como así lo vemos, por ejemplo, en el caso de la obra titulada Silla-ZAJ (1974) de Esther Ferrer: una "proposition $Z A J$ ” en la que, según el rótulo que incorpora, podemos sentarnos “jusqu’à ce que la mort vous sépare”. Algo parecido ocurría en otra obra titulada Música de cámara $n^{\circ} 268$ (1990) de Walter Marchetti, consistente en una 
cama, ya de por sí sugerente, que, repleta de cascabeles, invitaba a ser sonada por quien se atreviera a ello. Al respecto de estas últimas obras, podríamos decir que, acordes con el giro natural de la mayor parte de las prácticas artísticas contemporáneas, el componente participativo de las obras en ZAJ iría adquiriendo con el tiempo cada vez un mayor peso. El posible uso inesperado del objeto es, por tanto, lo que en ZAJ despertaba su sentido poético y no el objeto en sí mismo; de ahí que a la desmaterialización completa de la obra, tan solo quedase un paso.

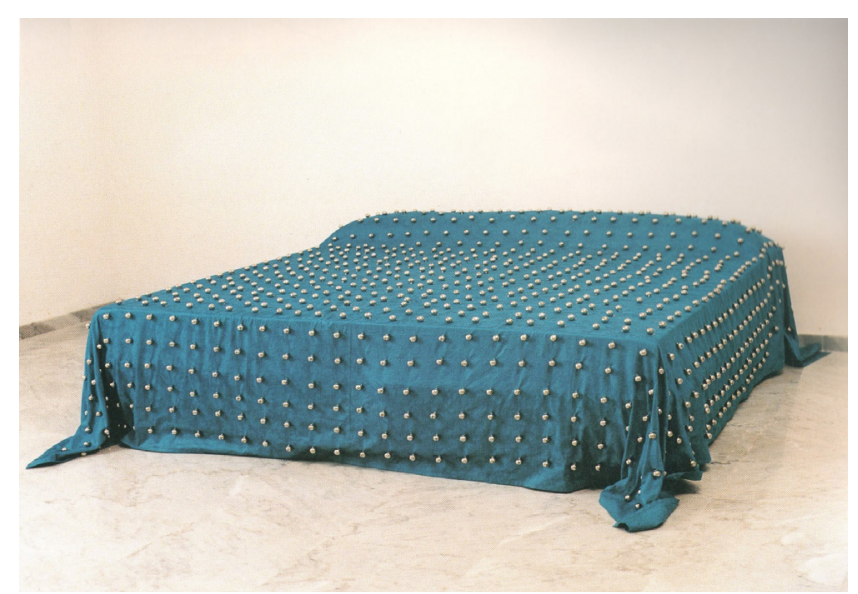

Figura 3: Walter Marchetti, Música de cámara n²68 (1990).

Se trata de un estadio que, en nuestro particular recorrido por las propuestas de ZAJ, bien pudiera corresponderse con toda la producción de textos que el grupo llevase a cabo. Por una parte, debemos señalar la existencia de tres libros fundamentales que sintetizarían las características de la poética zajiana: Viaje a Argel (1966) de Juan Hidalgo, La caida del avión en el terreno baldio (1967) de José Luis Castillejo y Arpocratesedutosul loto (1968) de Walter Marchetti. Tres obras que, desde distintas motivaciones, constituyen uno de los episodios más significativos de la poesía contemporánea española ${ }^{23}$. Las tres son frutos del puro azar compositivo y de la no-intencionalidad zajiana, creaciones que, continuando con el talante musical de la poética general del grupo, albergan caracteres lingüísticos junto a figuras geométricas de colores y espacios vacíos a los que se les da especial importancia. Como punto de unión, en este sentido, todos estos trabajos, que por su artificiosidad tienen mucho de lo que hoy denominaríamos "libro de artista", destacan por una divertida impronta musical rítmica como contrapunto de esa característica huida de cualquier tipo de narratividad lógica. Paralelo a estos tres libros-objeto,

23 Cf. José Antonio Sarmiento, La otra escritura: La poesía experimental española, 1960-1973, Cuenca, Servicio de Publicaciones de la Universidad de Castilla-La Mancha, 1990. 
debemos mencionar también la importancia de los llamados "cartones", un conjunto de tarjetas de invitación a conciertos o breves textos denominados "etcéteras" - por su naturaleza indescriptible- que, en cierto modo, y pese a su carácter reproductivo, pueden ser entendidas como piezas artísticas en sí mismas, capaces de llegar a articular todo un "concierto postal" sin necesidad alguna de sonidos. En efecto, encontramos piezas como Respire (1966) de Walter Marchetti, consistente en unas instrucciones para respirar, que, gracias a su fuerte a la vez que sutil -o "infraleve", diría Duchamp- potencial poético, pueden ser consideradas abiertamente como obras artísticas. Unos productos que, debido a la posibilidad de ser enviados por correo postal, incluían, además, una gran carga comunicativa y participativa. Como curiosidad, podríamos señalar el ejemplo de un cartón donde Marchetti anotó mediante una serie de trazos discontinuos la musicalidad propia del vuelo de una mosca y en cuyo reverso escribió: "ZAJ desea a todos sus amigos un año especial de meditación 1968 con la observación hecha por Walter Marchetti de los movimientos de una mosca sobre el cristal de una ventana desde las 8 de la mañana hasta las 7 de la tarde de un día de mayo de 1967"24.

De este modo llegamos al último tramo de nuestro camino, a la máxima esencialidad expresiva: la importancia que alcanzase en ZAJ el simple gesto. Un lenguaje que englobaría un conjunto de propuestas en las que se prescindiría de todo tipo de artefactos y códigos externos, objetuales o verbales, apostando sencillamente por el potencial poético del cuerpo como medio. En ellas, la obra se reduce a la presencia del ejecutante, que, al contrario que en el sofisticado modelo a la italiana, se sitúa al mismo nivel que el espectador para que este, si así lo cree oportuno, también participe. Una idea de participación libre que nos retrotraería al "teatro de la crueldad" de Antonin Artaud y a su particular búsqueda de la verdad y de la vida liberada, no en el teatro, sino más bien en la calle ${ }^{25}$. Como recordaba Esther Ferrer, con el Mayo del 68 a las puertas, "todo el mundo se considera, la participación era obligatoria. Tú podías hacer lo que querías pero el otro podía decir "oye, ¿qué estás haciendo? Esto es una mierda", quiero decirte, se contestaba todo: en las universidades a los profesores, en la calle a la policía. La contestación estaba allí, era fácil, entonces cuando hacías algo la gente se consideraba con el derecho a participar y sobre todo si se veían con algo que no entendían, eso era evidente"26. Así

24 El cartón se encuentra reproducido en:José Antonio Sarmiento (ed.) et al., ZAJ [Catálogo de la exposición]: Museo Nacional Centro de Arte Reina Sofía, 23 de enero - 21 de marzo, 1996, op. cit., p. 133.

25 Antonin Artaud, El teatro y su doble, E. Alonso y F. Abelenda (trads.), Barcelona, Edhasa, 1978 (1a Ed. 1938), p. 85.

26 Esther Ferrer, Entrevista con el autor, op. cit. La propia corriente situacionista y su dérive, con Debord al frente, simbolizarían a la perfección el ánimo contestatario de una sociedad, o al menos de un importante sector de esta, que veía -y sigue viendo- en el transitar y en la ocupación de la calle el escenario idóneo para llevar a cabo su lucha. 
lo vemos en El caballero de la mano en el pecho (1967), de Eugenio de Vicente, algo así como una reinterpretación de la famosa obra de El Greco, justo antes de que un espontáneo saltara al escenario y continuara él mismo la acción. Se trataba de una experimentación performativa abierta que, en última instancia, llevaría un uso del cuerpo desnudo como medio de experimentación en sí mismo. Como muestra, valdría recordar la obra titulada Flor y hombre (1969), perteneciente al trabajo individual de Hidalgo, donde el autor exploraría la poeticidad del desnudo masculino sin dejar de lado sus implicaciones sexuales, o Íntimo y personal (1971), una de las acciones o performance más conocidas de Esther Ferrer, consistente en una toma de medidas de diferentes cuerpos para repensar la realidad existente tras los estereotipos establecidos. Todas ellas, reflexiones que continuarían en otras obras como Biozaj (1977), en la que se fundían los cuerpos masculino y femenino favoreciendo la reflexión sobre la condición transexual frente al alcance de los condicionamientos sociales.

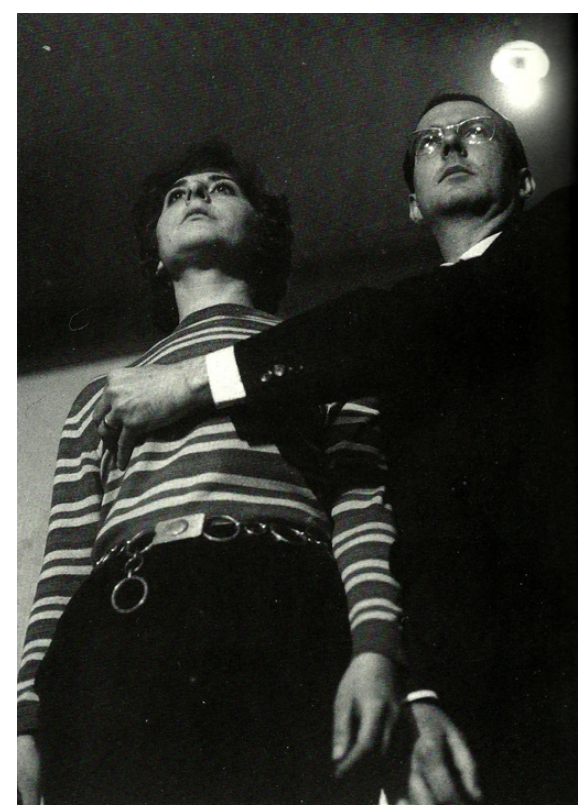

Figura 4: Esther Ferrer y Juan Hidalgo interpretando El caballero de la mano en el pecho, de Eugenio de Vicente (Düsseldorf, 1968).

Como hemos intentado mostrar resumidamente, la particular poética de ZAJ, basada en el gesto nimio y absurdo frente a una realidad marcada por las rígidas directrices del gobierno franquista y su característica coerción de las libertades individuales y colectivas, escapaba de algún modo no solo a los márgenes tradicionales del arte, sino también, como consecuencia de esto, a aquellos rígidos parámetros estéticos del arte oficial de la dictadura ${ }^{27}$. En relación a lo 
primero, la propuesta zajiana constituía un viaje de ida y vuelta entre el trabajo plástico y la acción inmaterial, si bien, en cualquier caso, debemos hablar de un tipo de obra que siempre aspira a su mínima expresión o, quizás mejor, que no teme aparecer -de hecho le resulta indiferente- como un producto pobre. Un rasgo que se veía favorecido por la naturaleza de los materiales utilizados o por el interés en prácticas como la del envío postal (actividad que contribuía significativamente a una democratización radical del concepto de arte tradicional), pero que tenía que ver sobre todo con ese tipo de "autosuficiencia vital" a la que impelía el contexto dictatorial, reflejada tanto en la obligación de un valerse por sí mismo, como en el afán por reinventarse continuamente ante las múltiples adversidades. En todo caso, el hecho de dirigir su filosofía creativa hacia un terreno situado a las puertas del no-arte colocaba automáticamente a ZAJ lejos de la influencia del afán regulador del sistema artístico. A partir de este punto, comprendiendo dicho sistema como reflejo a escala del macrosistema social franquista, podríamos pensar ZAJ como un auténtico hito de resistencia en la medida en que dirigía directa o indirectamente su sutil potencial político contra el efecto neutralizador que operaba en todos los campos de la vida pública y privada. A este respecto, debemos ser conscientes de que eran los propios integrantes del grupo quienes, entre otras cosas, se encargaban de patrocinar los eventos cuidando hasta el más mínimo detalle, desarrollando así sus propuestas con total independencia de la opinión crítica oficial y, en general, defendiendo una completa libertad creativa y reflexiva como ningún otro ejemplo espańol de aquellos momentos ${ }^{28}$.

En segundo lugar, conviene recalcar la influencia del Zen en la filosofía creativa de ZAJ, auténtico configurador del modo en que el grupo diese forma a su singular actitud de resistencia política. Un elemento que, aunque desapercibido a veces, es posible encontrar en el arte contemporáneo desde las propias Vanguardias Históricas de principios del siglo XX hasta la esencia del arte conceptual ${ }^{29}$. El Zen en occidente, donde solo comenzó a calar en

28 Sobre la opinión de la crítica oficial, merece la pena destacar la extraordinaria recopilación de artículos sobre la serie de Conciertos ZAJ celebrados en el Teatro Infanta Beatriz de Madrid -9, 16 y 23 de febrero y 2 de mayo de 1967- que aporta el catálogo de la gran exposición antológica sobre ZAJ celebrada en el MNCARS que hemos citado en varias ocasiones. Un breve repaso por sus títulos bastará para hacernos una idea del talante de los textos: "ZAJ: Espectáculo inusitado" (M. Escribano, El Alcázar, 11/02/1967); "Suspensión acertada" (S. Adame, en Pueblo, 18/02/1967); "ZAJ, esbozo de "happening" en el Teatro Beatriz" (L. López, en $A B C, 11 / 02 / 1967)$; o "ZAJ, "verdadera tontería" -no calificamos nosotrosescenificada en el Beatriz" (J. Téllez, en Hoja del lunes, 13/02/1967).

29 Cf. Juan Bahk, Surrealismo y Budismo Zen: Convergencias y divergencias, Estudio de literatura comparada y antología de poesía Zen de China, Corea y Japón, Madrid, Verbum, 1997; Diego Luna, "A partir de Courant d'air sur le pommier du Japon: Principios estéticos japoneses en la obra de Marcel Duchamp", en Fedro. Revista de Estética y Teoría de las Artes [En línea] $\mathrm{n}^{\circ} 14,2015$. Disponible en:<http://institucional.us.es/fedro/uploads/pdf/n14/luna.pdf> [Último acceso: 10/05/2015]. 
la sociedad en los años treinta del siglo XX, llegó a tener especial relevancia en la filosofía de la Contracultura de los sesenta y setenta. Muestra de ello es el hecho de que Juan Hidalgo se decantase muy joven por dedicar sus estudios universitarios a la cultura oriental -formación a la que tuvo acceso en Italia-, algo verdaderamente insólito en la hermética España de los primeros años cincuenta. En general, el Zen en el arte conlleva una alteración total, no solo de la sintaxis lógica, sino también, en cuanto a percepción y experiencia estética, del recorrido del sujeto hacia el objeto artístico ${ }^{30}$, lo que en la cultura moderna supondría el fin de su característica dualidad logocentrista. De este modo, en los escritos de ZAJ, al igual que en el koan japonés, vehículo predilecto del Zen, tenía lugar una recuperación de la mirada intuitiva capaz de superar en muchos sentidos nuestra tradicional mirada cientificista. Como hemos podido desarrollar en otra ocasión, muchos son los vínculos que se podrían establecer entre el koan y el etcétera zajiano, e incluso el ready-made duchampiano ${ }^{31}$. Uno de ellos es el que adopta como único patrón la total apertura semántica y, por ende, la falta de un sentido concreto así como la validez de cualquiera de ellos. A este respecto, la acción de Hidalgo titulada El recorrido japonés (1963) resultaría paradigmática: una obra consistente en hacer -solo o acompañado, con un objeto o sin él, y con la duración que se estimase oportuna-algo.

En tercer y último lugar queremos destacar el componente participativo. Como hemos visto, fenómenos como ZAJ, en cuya misma órbita debemos situar a Fluxus -considerados sus "parientes lejanos" -, defendían un arte que paradójicamente no debía conllevar una dificultad mayor que la inducida por cualquier actividad cotidiana. Un arte que perseguía por encima de todo disolver el arte en la vida, pretensión que, al tiempo que recuperaba la esencia del proyecto político que en sí mismo se constituye en las Vanguardias Históricas ${ }^{32}$, atentaba contra toda la tradición occidental de los últimos cinco siglos. En ZAJ, el interés por penetrar en la vida misma de los individuos parece claro si atendemos a la importancia del envío postal como práctica artística, cuyo mecanismo conseguía llegar con facilidad al mismo ámbito privado. También en el Concierto ZAJ, sin duda la expresión más completa y genuina del grupo, observamos un especial interés por fomentar un acto de vida colectiva más propio de la vida en el foro y los cultos antiguos, en los que, como sabemos, la música tenía un papel protagonista, que de los elitistas espectáculos modernos de gran aparataje escénico, únicamente accesibles a una clase pudiente y dominante: "La sensibilidad de lo actual -dijo

30 Se recomienda ver el resumen de las características esenciales del Zen, así como del arte y la cultura de Japón, en: Daisetsu Teitaro Suzuki, El Zen y la cultura japonesa, M. Tabuyo y A. López (trads.), Barcelona, Paidós, 1996, p. 22 y ss.

31 Cf. Diego Luna, ZAJ: Arte y política en la estética de lo cotidiano, op. cit., p. 174-199.

32 Cf. Peter Bürger, Teoría de la Vanguardia, J. García (trad.), H. Piñón (pról.), Barcelona, Península, 1987. 
José Luis Castillejo- tiende a ser más libre porque invita a la participación generalizada, la cual pide, por cierto, que se enfríe el suceso estético si se quiere evitar las redundancias extremas" ${ }^{33}$. Resulta evidente, de hecho, la conexión entre ZAJ y su contexto internacional en el sentido en que su capacidad creativa consiguió traspasar las fronteras de la individualidad para tomar conciencia de que, como defendiera Herbert Marcuse y simbolizara el Mayo Francés, el trabajo artístico debía funcionar como instrumento crítico, perturbador y decisivo en la lucha por la libertad.

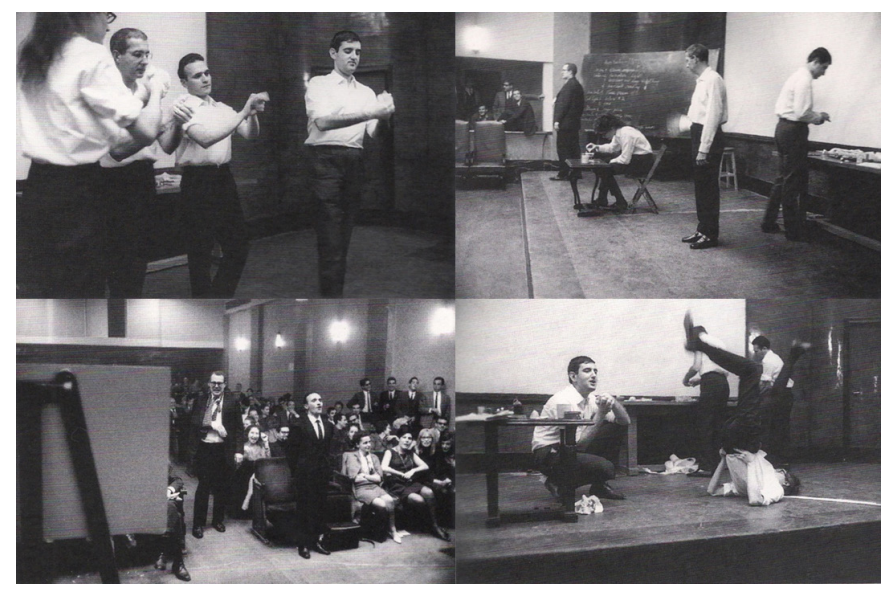

Figura 5: Concierto ZAJ, Events y New Music, con la colaboración de los artistas fluxus Alison Knowles y Dick Higgins (Madrid, 1966).

Sencillez, expansión de la conciencia y participación. La inmanencia del gesto cotidiano suponía precisamente, frente a la naturaleza divina en la que se apoyaron ideológicamente algunos regímenes totalitarios del siglo XX, esa libertad interior que escapaba a todo intento de coerción política y que, como ocurría en el caso de ZAJ, servía como fundamento para establecer un espacio relacional alternativo en el que superar lo que Erich Fromm identificase como la "soledad moral" ${ }^{34}$. Ante la adversidad y la represión de una política fuertemente estetizada en torno a la figura de un caudillo-artista (el cual, en tanto que escultor, manipulaba la sociedad como un bloque de arcilla entre sus manos), la mejor manera de cultivar el compromiso social y la fortaleza interior era, a la inversa, mediante las posibilidades de una estética politizada en la que, como Joseph Beuys propusiera, todo el mundo podía ser un artista. Una vez asumidos los riesgos de intentar esquivar la censura desde la práctica artística, el propio vivir directamente, esto es, de una forma atenta, que propugnaban tanto ZAJ como su "pariente extranjero" Fluxus, acababa

33 José Luis Castillejo, Actualidad y participación:Una filosofía contemporánea, Madrid, Editorial Tecnos, 1969, p. 23.

34 Erich Fromm, El miedo a la libertad, G. Germani (trad.), Buenos Aires, Paidós, p. 45. 
desbordando, de hecho, todos los límites simbólicos de lo que Rancière denominase el "régimen estético de las artes"35. Las propuestas de ZAJ planteaban, en definitiva, el desafío de hacer una poética anarquista de la vacuidad, nihilista, del algo como pretexto. Su verdadera poética residía pues en la osadía de la inmanencia de hacer o mostrar cualquier cosa, al margen de la realidad fragmentada que conformaba un lenguaje tan discriminador como el existente solo en los momentos de especial segmentación cultural. Una de las presentaciones más célebres del grupo con la que comenzábamos estas reflexiones ("ZAJ es ZAJ porque ZAJ es no-ZAJ") parece advertirnos de que principio y fin solo pueden estar en ZAJ mismo. Esta es, finalmente, la particular forma en que ZAJ, desde la resistencia más silenciosa en tanto que incomprensible a ojos legos, recuperaba la autenticidad perdida de la verdadera causa artístico-social de la Vanguardia; aquella que, gracias al inefable poder de un algo que, por cierto, se encontraba en cualquier parte de la realidad inmediata - no mediada-, proponía una forma alternativa de pensar y actuar.

\section{Diego Luna Delgado}

Universidad de Sevilla

dielundel@gmail.com

\section{Resumen}

El grupo artístico español ZAJ, activo entre 1964 y 1996, es hoy un ejemplo paradigmático de la manera en que fue posible el desarrollo de ciertas formas de resistencia política contra los estrictos y represivos parámetros culturales del franquismo. Una breve aproximación a los novedosos espacios intermedios de expresión que el colectivo desarrollase (música de acción, arte postal, derivas urbanas, etc.) revela el potencial político de un arte basado en el desmantelamiento de las fronteras formales y conceptuales.

\section{Palabras claves}

ZAJ, música de acción, franquismo, contracultura, Zen.

\section{Résumé}

Le groupe artistique espagnol ZAJ, actif entre 1964 et 1996, est aujourd'hui un exemple paradigmatique de la manière dont il était possible de développer certaines formes de résistance politique contre les paramètres culturels stricts et répressifs du franquisme. Un bref aperçu des nouveaux espaces intermédiaires d'expression que le collectif développa (musique d'action, mail art, urbaine dérive, etc.) révèle le potentiel politique d'un art basé sur le démantèlement des frontières formelles et conceptuelles.

\section{Mots-clés}

ZAJ, musique d'action, franquisme, contre-culture, Zen.

35 Jacques Rancière, El reparto de lo sensible, C. Durán et al. (trads.), Santiago de Chile, LOM, 2009, p. 24. 


\begin{abstract}
The Spanish artistic group ZAJ, active between 1964 and 1996, is nowadays a paradigmatic example of how it were possible certain forms of political resistance in front of the strict and repressive cultural parameters of the francoism. A brief overview through the new intermediate spaces of expression that this phenomenon developed (action music, mail art, urban drift, etc.), reveals the functioning of the political potential of an art based on the dismantling of formal and conceptual limits.
\end{abstract}

\title{
Keywords
}

ZAJ, action music, francoism, contraculture, Zen. 